\title{
Eighteen years of clinical experience with a modification of the Bentall button technique for total root replacement
}

\author{
Dimos Karangelis, Dimitrios Tzertzemelis, Alexandros A. Demis, Stella Economidou, Matthew Panagiotou \\ Cardiac Surgery Department, Athens Medical Center, Distomou 5, Amaroussio 151 25, Greece \\ Contributions: (I) Conception and design: D Karangelis, M Panagiotou; (II) Administrative support: S Economidou, M Panagiotou; (III) Provision \\ of study materials or patients: D Tzertzemelis, AA Demis; (IV) Collection and assembly of data: D Tzertzemelis, AA Demis; (V) Data analysis and \\ interpretation: D Karangelis, D Tzertzemelis, S Economidou; (VI) Manuscript writing: All authors; (VII) Final approval of manuscript: All authors. \\ Correspondence to: Matthew Panagiotou, MD, FECTS. Cardiac Surgery Department, Athens Medical Center, Distomou 5, Amaroussio 151 25, \\ Greece. Email: mspanag@otenet.gr.
}

\begin{abstract}
Background: We retrospectively reviewed our experience with the modified Bentall procedure and evaluated the short- and long-term results over a period of 18 years.

Methods: Between 1999 and 2017, 89 patients with a mean age of $57.3 \pm 13.9$ years underwent the modified Bentall operation with a slight modification for the correction of aortic root disease.

Results: The operative mortality was $1.1 \%$ while the overall early mortality rate, defined as death within 30 days of initial hospitalization, was 2.2\% (2/89). Logistic regression analysis revealed that increased Euroscore and aortic cross-clamp times were associated with greater likelihood for complications. The overall survival rates for the 89 patients (including deaths occurred at the initial hospitalization) were $93.0 \%$ $(\mathrm{SE}=3.0 \%)$ at 6 months, $93.0 \%(\mathrm{SE}=3.0 \%)$ at 1 year, $89 \%(\mathrm{SE}=5.0 \%)$ at 5 years and $73.0 \%(\mathrm{SE}=5.0 \%)$ at 10, 15 and 18 years. Multiple Cox regression analysis for survival identified that increased aortic crossclamp time, increased age, having a concomitant cardiac procedure and increased NYHA Class were associated with greater hazard. Left ventricular remodeling was assessed by means of echocardiography preoperatively and 1, 3,6 and 12 months postoperatively.

Conclusions: According to our experience, the Bentall procedure is a safe procedure, provides optimal long-term survival and can still be regarded as the gold standard procedure for aortic root replacement.
\end{abstract}

Keywords: Aortic aneurysm; Bentall procedure; cardiac surgery; aortic root replacement

Submitted Jul 10, 2018. Accepted for publication Sep 29, 2018.

doi: $10.21037 /$ jtd.2018.11.61

View this article at: http://dx.doi.org/10.21037/jtd.2018.11.61

\section{Introduction}

Aortic root pathology is a unique field in the cardiac surgery arena and this is advocated by the evolution of aneurysmal surgery during the last two decades. Since Denton Cooley's and Michael De Bakey's first successful surgical intervention in the ascending aorta in 1956 (1), cardiac surgery has significantly progressed. Almost a decade later, Bentall and De Bono (2), described their technique for the implantation of the composite valve graft, an operation which until today has made a significant impact for patients with aortic root abnormality and dilated ascending aorta and is considered one of the most curative surgical procedures in medicine. In the following years distinctive surgeons like David and Yacoub have left their indelible mark in aortic surgery by repairing the aortic root while preserving the valve $(3,4)$. Over the last years we have witnessed a growing interest for aortic valve sparing (AVS) operations which aim at preserving the patient's native valve and mainly promise the benefit of eliminating the need for life-long anticoagulation. However, these operations are more technically demanding than the simple modified Bentall procedure and still carry some inherent risks such as reoperation for recurrent aortic insufficiency (AI) (5). Bentall is a widely popular operation 
Table 1 Demographics and preoperative characteristics

\begin{tabular}{|c|c|}
\hline Demographics and characteristics & $\mathrm{N}(\%)$ \\
\hline \multicolumn{2}{|l|}{ Sex } \\
\hline Women & $11(12.4)$ \\
\hline Men & $78(87.6)$ \\
\hline Age, mean (SD) (years) & $57.3(13.9)$ \\
\hline \multicolumn{2}{|l|}{ Smoking status } \\
\hline No & $28(38.4)$ \\
\hline Current & $26(35.6)$ \\
\hline Ex & $19(26.0)$ \\
\hline Hypertension & $74(83.1)$ \\
\hline Coronary artery disease & $20(22.5)$ \\
\hline Chronic kidney disease & $3(3.4)$ \\
\hline Diabetes mellitus & $14(15.7)$ \\
\hline History of pulmonary disease & $11(12.4)$ \\
\hline History of preop neurological disease & $5(5.6)$ \\
\hline Pre-op arrhythmias & $12(13.5)$ \\
\hline \multicolumn{2}{|l|}{ NYHA class } \\
\hline I & $57(67.9)$ \\
\hline II & $12(14.3)$ \\
\hline III & $13(15.5)$ \\
\hline IV & $2(2.4)$ \\
\hline Euroscore I, mean (SD) & $11.0(7.2)$ \\
\hline Diameter of aorta, mean (SD) & $55.7(6.6)$ \\
\hline Marfan & $2(2.2)$ \\
\hline Previous cardiac surgery & $10(11.2)$ \\
\hline \multicolumn{2}{|l|}{ Grade of aortic regurgitation } \\
\hline None & $6(8.8)$ \\
\hline Mild & $11(16.2)$ \\
\hline Moderate & $23(33.8)$ \\
\hline Severe & $28(41.2)$ \\
\hline Ejection fraction, mean (SD) & $50.4(17.3)$ \\
\hline \multicolumn{2}{|l|}{ Aortic pathology } \\
\hline Annuloaortic ectasia (tricuspid valve) & $62(69.7)$ \\
\hline Annuloaortic ectasia (bicuspid valve) & $21(23.6)$ \\
\hline $\begin{array}{l}\text { Bicuspid aortic valve + aortic } \\
\text { stenosis + aortopathy }\end{array}$ & $2(2.2)$ \\
\hline Dissection (acute/chronic) & $3 / 1(4.4)$ \\
\hline
\end{tabular}

and as the experience with it increased, its indications have expanded to a variety of other conditions including aortic dissections and infective endocarditis with aortic root abscess (6-8). Nevertheless, patients with annuloaortic ectasia still represent "the bread and butter" of Bentall procedure. This is a small series of patients who underwent a Bentall procedure and it represents results from a single center. With this study we aim to evaluate the effectiveness of the modified Bentall procedure by retrospectively reviewing our short- and long-term results of our 18-year experience in our pool of 89 patients.

\section{Methods}

After receiving the institutional board approval (Protocol number $3345,6^{\text {th }}$ March 2018), we started our retrospective data collection. From January 1999 to June 2017, 89 patients underwent the modified Bentall procedure for various indications such as chronic aneurysm of the ascending aorta with aortic root pathology [aneurysmal root, concomitant severe AI, aortic stenosis (AS) and poststenotic dilatation] or type A dissection.

Seventy-eight $(87.6 \%)$ were male and 11 were female (13.9\%). Two patients were identified as Marfanoid phenotype (2\%), according to the revised Ghent criteria. We identified 23 patients with bicuspid aortic valve, 2 of which had AS as their primary pathology. The final database included demographics, types of indications, comorbidities, procedure specifications and follow-up information. Medical records and patient's history were used to identify comorbidities (Table 1). Patients' follow-ups included clinical examination, transthoracic echocardiography and computed tomography scans, when possible. In some cases, follow-up data were gathered with direct telephone interview or contact with the patient's cardiologist. The primary indication for surgery was annuloaortic ectasia $(93.3 \%)$ while aortic dissection, acute or chronic, was observed in 4 patients (4.5\%) (Table 1).

\section{The surgical technique}

All patients were operated with the modified Bentallbutton technique. The standard approach for all the operations was median sternotomy. Cardiopulmonary bypass was established by arterial cannulation of aortic arch, femoral or axillary artery depending on the extension of the aneurysm to the ascending aorta or the presence of aortic dissection. Venous cannula was inserted in the 
right atrium. The majority patients were operated with moderate hypothermia $\left(\right.$ at $28^{\circ} \mathrm{C}$ ) and myocardial protection was achieved by antegrade and retrograde intermittent cold blood cardioplegia and topical cooling (slash). If circulatory arrest was required, the patient was cooled down to $18{ }^{\circ} \mathrm{C}$ and antegrade cerebral perfusion was instituted via axillary artery cannulation and selective left common carotid cannulation. Right superior pulmonary vein was adopted for venting the left ventricle. Attention was given to the construction of small (aortic tissue $<5 \mathrm{~mm}$ ) buttons. Our modification of the classical modified Bentallbutton technique lies in that we perform the distal graft anastomosis before the right coronary artery (RCA) button (distal first-RCA last). Once the distal anastomosis is completed, the graft is pressurized by delivery of antegrade cardioplegia. Subsequently, the exact site of the RCA button is determined on the fully expanded skirt of the conduit. This small detail offers a better estimation of the optimal RCA button site, eliminating any possible strain on the anastomosis that would potentially compromise flow.

\section{Statistical analysis}

Quantitative variables were expressed as mean values and standard deviation (SD) or with median and interquartile range (IQR), while qualitative variables were expressed as absolute and relative frequencies. Student's $t$-tests were computed for the comparison of mean values between two groups. Life table analyses were used to calculate cumulative survival rate (standard errors) for specific time intervals. Multiple Cox proportional-hazard model in a stepwise method ( $\mathrm{P}$ for removal was set at 0.1 and $\mathrm{P}$ for entry was set at.05) was used in order to identify significantly associated variables with survival (9). The assumption of proportional hazards was evaluated by testing for interaction with a continuous time variable. Hazard ratios (HR) with $95 \%$ confidence intervals ( $95 \% \mathrm{CI}$ ) were computed from the results of the Cox regression analysis. Kaplan-Meier survival estimates were graphed over the follow-up period. Log rank tests were used to compare survival curves. Multiple stepwise logistic regression analysis was used in order to find independently associated factors with postoperative complications. Odds ratios (OR) with $95 \%$ CI were computed from the results of the logistic regression analysis. Changes of left ventricular end diastolic diameter (LVEDD) and left ventricular end systolic diameter (LVESD) during the follow-up period of 1 year were evaluated using repeated measurements analysis of variance (ANOVA). All reported $\mathrm{P}$ values are two-tailed. Statistical significance was set at $\mathrm{P}<0.05$ and analyses were conducted using SPSS statistical software (version 22.0).

\section{Results}

\section{Preoperative data}

Our sample consisted of 89 patients (78 men and 11 women) with mean age 57.3 years $(\mathrm{SD}=13.9)$. Sample demographics and preoperative characteristics are presented in Table 1. Hypertension, coronary artery disease and diabetes were present in $83.1 \%, 22.5 \%$ and $17.9 \%$, respectively. Preoperative arrhythmias were present at 12 patents (13.5\%) and the mean Euroscore was $11.0(\mathrm{SD}=7.2)$. Fifteen patients $(17.9 \%)$ had NYHA class III or IV and $11.2 \%$ had previous cardiac surgery. The grade of aortic regurgitation was moderate at $33.8 \%$ and severe at $41.2 \%$ of the sample.

\section{Perioperative data}

The mean cross-clamp time was 144.5 minutes (IQR: 131-160 minutes) and $95.5 \%$ of the procedures were elective; no significant difference was observed when the elective procedures $(85,95.5 \%)$ were compared with the non-elective ones $(4,4.5 \%)(\mathrm{P}=0.920)$. Deep hypothermic circulatory arrest (DHCA) was utilized in 7 patients (7.9\%). Perioperative characteristics are shown in Table 2.

The most frequently used composite grafts were the St. Jude Medical (St. Jude Medical, Inc., Minnesota, MN USA) composite graft (58 patients), followed by the Carboseal Valsalva conduit (LivaNova Group, Milan, Italy) (25 patients). In the last 22 patients, the Valsalva graft (LivaNova Group, Milan, Italy) was the preferred conduit. The comparison between the Valsalva and non-Valsalva grafts revealed no difference in the cross clamp or bypass times in these two groups $(\mathrm{P}=0.438$ and $\mathrm{P}=0.402$ respectively).

Concomitant procedures were performed in 14 patients $(15.7 \%)$. These included mitral valve surgery in 3 , coronary artery bypass grafting (CABG) in 9 , hemi- and total arch replacement in 2. The mean hospital stay was 9.4 days $(\mathrm{SD}=2.8)$ and the mean intensive care unit (ICU) stay was 2.3 days $(\mathrm{SD}=2.0)$.

\section{Early outcomes}

The operative mortality was $1.1 \%$. The overall early mortality rate, defined as death within 30 days of initial 
Table 2 Perioperative characteristics

\begin{tabular}{lc}
\hline Perioperative characteristics & Value \\
\hline Graft type, N (\%) & $58(65.2)$ \\
St. Jude Medical & $25(28.1)$ \\
Carboseal Valsalva conduit & $6(6.7)$ \\
Others & $14(15.7)$ \\
Concomitant cardiac procedures, N (\%) & $3(3.4)$ \\
Mitral valve surgery & $9(10.1)$ \\
Coronary artery bypass & $2(2.2)$ \\
Hemiarch replacement & \\
Cardiopulmonary bypass & $179(158.5-194.5)$ \\
CPB time, median (IQR) (min) & $144.5(131-160)$ \\
Aortic cross-clamp time, median (IQR) & \\
(min) & $7(7.9)$ \\
DHCA use, N (\%) & $26.0(5.7)$ \\
Pharyngeal temperature, mean (SD) $\left({ }^{\circ} \mathrm{C}\right)$ & \\
Timing of operation, N (\%) & \\
Urgent & \\
Elective & \\
ICU stay, mean (SD) (days) & \\
\hline
\end{tabular}

$I Q R$, interquartile range; ICU, intensive care unit.

Table 3 Intraoperative and early postoperative complications

\begin{tabular}{lc}
\hline Complications & $\mathrm{N}(\%)$ \\
\hline Intraoperative complications & \\
Bleeding-death & $1(1.1)$ \\
Early postoperative complications & \\
Any complication & $17(19.1)$ \\
Reopening for bleeding/tamponade & $5(5.6)$ \\
CVA (or TIA) & $2(2.2)$ \\
New arrhythmias & $5(5.6)$ \\
Pacemaker & $3(3.4)$ \\
New haemofiltration or dialysis & $5(5.6)$ \\
\hline
\end{tabular}

CVA, cerebrovascular accident; TIA, transient ischemic attack.

hospitalization, was $2.2 \%$ (2/89). Causes of early death were low cardiac output syndrome $(n=1)$, and excess bleeding in one patient with aortic dissection. Early
Table 4 Results from multiple logistic regression analysis in a stepwise method with dependent variable the existence of postoperative complications

\begin{tabular}{lcc}
\hline Variables & OR $(95 \% \mathrm{Cl})^{+}$ & P value \\
\hline Euroscore II & $1.11(1.01-1.24)$ & 0.035 \\
Aortic cross-clamp time $(\mathrm{min})$ & $1.09(1.01-1.31)$ & 0.042 \\
\hline${ }^{+}$, odds ratio $(95 \%$ confidence interval).
\end{tabular}

complications were recorded in 17 of the cases (19.1\%) and included postoperative resternotomy for bleeding (5.6\%), cerebrovascular accident (CVA) (2.2\%), new arrhythmias $(5.6 \%)$, pacemaker $(3.4 \%)$ and hemofiltration or dialysis (5.6\%) (Table 3).

When multiple logistic regression analysis was performed in a stepwise method with dependent variable the existence of postoperative complications (Table 4), it was found that increased Euroscore was associated with greater likelihood for complications. Additionally, it was found that increased aortic cross-clamp time was associated with greater odds for having complications.

\section{Long-term results}

To date, the mean survival is 10 years $(\mathrm{SE}=1.2)$. There have been seven late deaths. There was one cardiac (heart failure) and six non-cardiac deaths (1 prostate cancer, 1 aplastic anaemia, 1 alcoholic pancreatitis, 1 sepsis, 1 trauma, 1 pneumonia leading to multiple organ failure). The overall survival rates for the 89 patients (including deaths occurred at the initial hospitalization) were $93.0 \%$ [standard error $(\mathrm{SE})=3.0 \%$ ] at 6 months, $93.0 \%(\mathrm{SE}=3.0 \%)$ at 1 year, $89 \%(\mathrm{SE}=5.0 \%)$ at 5 years and $73.0 \%(\mathrm{SE}=5.0 \%)$ at 10,15 and 18 years.

Kaplan-Meir curve for overall survival rates is presented in Figure 1. A comparison between the straight tube graft and the Valsalva one, showed no significant differences (log-rank test, $\mathrm{P}=0.407$ ).

Multiple Cox regression analysis for survival (Table 5) identified that increased aortic cross-clamp time, increased age, having a concomitant cardiac procedure and increased NYHA class were associated with greater hazard.

\section{Follow-up outcomes}

During follow-up, three patients developed superficial wound infection $(3.4 \%)$. New bleeding events occurred in 3 patients (3.4\%) with all the patients recovering well. At 


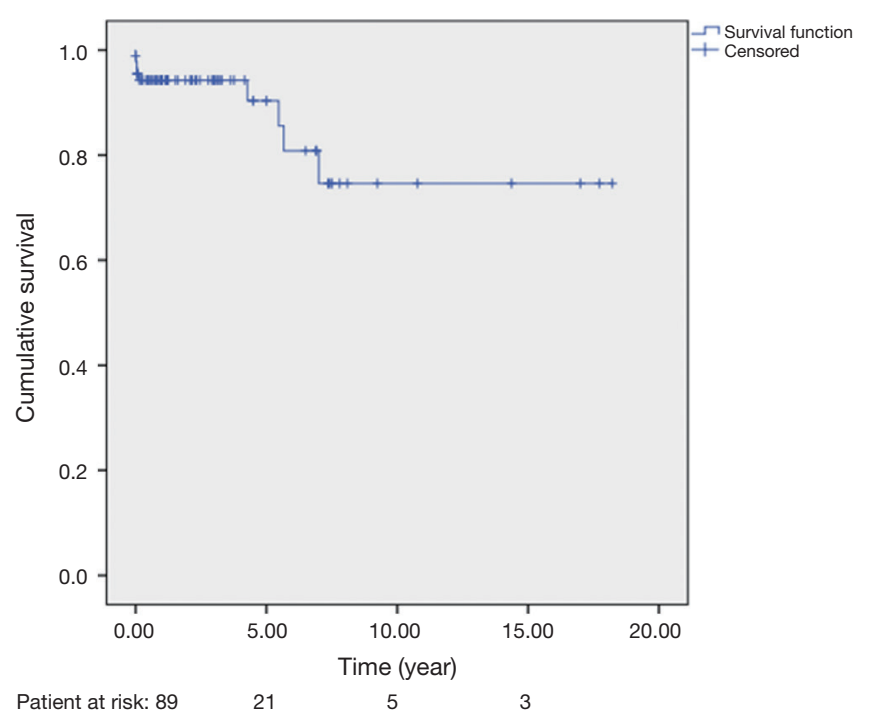

Figure 1 Kaplan-Meir curve for overall survival rates.

Table 5 Results from multiple Cox regression analysis in a stepwise method for survival

\begin{tabular}{lcc}
\hline Variables & $\mathrm{HR}(95 \% \mathrm{Cl})^{+}$ & $\mathrm{P}$ value \\
\hline Aortic cross-clamp time $(\mathrm{min})$ & $1.03(1.01-1.04)$ & $<0.001$ \\
Age & $1.07(1.01-1.13)$ & 0.048 \\
Concomitant cardiac procedure & $2.55(1.26-5.19)$ & 0.009 \\
NYHA class & $2.73(1.27-5.84)$ & 0.010 \\
\hline
\end{tabular}

${ }^{+}$, hazard ratio (95\% confidence interval).

the time of bleeding the International Normalized Ratio (INR) was 3.58, 4.01 and 3.03 respectively.

After liaising with every patient's cardiologist, all patients were submitted to regular echocardiograms at 1, 3, 6 and 12 months postoperatively. Transthoracic echocardiogram was used to evaluate the incidence of left ventricle remodelling. The two cases of bicuspid valve AS and all acute aortic dissection patients (4 patients) were excluded.

The comparison of the mean values of LVEDD (Figure 2) and LVESD (Figure 3) using repeated measurements ANOVA showed significant differences between the preoperative values and their respective values 1, 3, 6 and 12 months postoperatively with the exception of the comparison of LVESD preoperative to one month. A constant decrease in LVEDD and LVESD during the 12 months follow-up was found.

All the patients at follow-up were free from structural valve deterioration or necessity of re-operation for valve

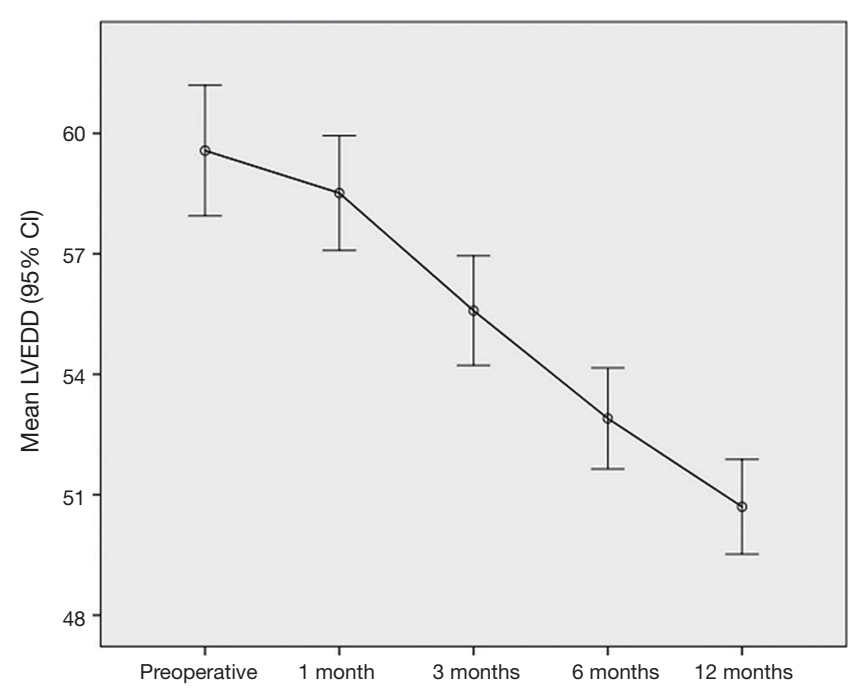

Figure 2 Comparison of the preoperative and postoperative (1, 3, 6 and 12 months) mean values of LVEDD. LVEDD, left ventricular end diastolic diameter.

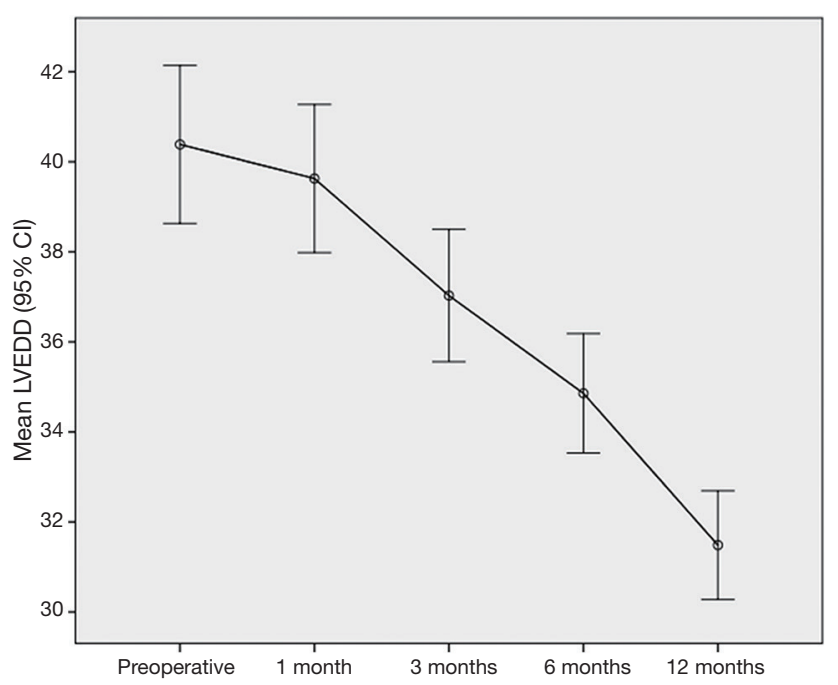

Figure 3 Comparison of the preoperative and postoperative (1, 3, 6 and 12 months) mean values of LVESD. LVESD, left ventricular end systolic diameter.

thrombosis, prosthetic valve endocarditis, pseudoaneurysm and pannus formation.

\section{Discussion}

In 1968, Bentall and De Bono described an operation for treating patients with aortic root aneurysms, which 
consisted of reconstruction of the aortic root with a valved composite graft and direct end-to-side implantation of the coronary ostia to the prosthetic graft, without excision of the aneurysmal portion of the aorta. This technique, namely the Bentall inclusion technique, became the standard practice for surgical treatment for many years. However, this method was complicated by increased rates of bleeding in the perigraft space, coronary detachment due to tenuous coronary anastomosis, formation of false aneurysms and dehiscence of the proximal aorta-to-graft anastomosis and perigraft space fistulas $(2,10)$. Since then, several techniques have been developed to reduce the rate of complications and improve patient outcomes. The aneurysm exclusion technique by Kouchoukos and colleagues has led to a significate drop in the afore-mentioned complications (11). Currently, the use of the modified Bentall technique that involves coronary button mobilization and then attachment of the ostial buttons to the graft has been adopted by the vast majority of cardiac surgery centers worldwide (12). Our study presents the results of our 18-year experience with a slight modification of the modified Bentall-button technique.

Over the last decades, there has been a documented considerable improvement in mortality rates in patients submitted to the Bentall procedure. Early and hospital mortality range between $0.7 \%$ to $12 \%$ in most studies (13-15). The disproportionate percentages in early mortality among several reports could be explained by different patient populations, i.e., reported Euroscore rates, concomitant procedures, and modifications in operative techniques or postoperative management strategies. Benke et al., on a total of 147 patients who underwent aortic root reconstruction reported an overall early mortality rate of $3.4 \%$ (16). The authors recognized concomitant surgery (CABG and mitral valve) as independent predictor of early complication but this however, was not translated as a risk factor for mortality in their study. Multiple Cox regression analysis for survival in our study has shown that, concomitant procedures along with increased aortic cross-clamp time, age and increased NYHA Class were associated with greater hazard. We have found that early mortality in our patients $(2.2 \%)$, is comparable with that of the previous studies but we have to acknowledge that most of our patients were operated on an elective basis and our cohort comprised of patients with a mean age of $57.2 \pm 13.9$ years.

With regards to postoperative complications the Bentall procedure is also considered to be a safe procedure. Hagl and colleagues (15), reported an incidence of $1.4 \%$ for re- exploration for bleeding and $1.4 \%$ for postoperative stroke while Zehr and colleagues (5), reported a re-exploration for bleeding rate of $4 \%$ and a stroke rate of $1.0 \%$. We have reported a reopening for bleeding rate of $5.6 \%$ and a renal failure requiring hemodialysis rate of $5.6 \%$, however, 10 of our patients underwent a redo procedure and another 14 patients $(15.7 \%)$ had a concomitant procedure along with the Bentall.

As far as the long-term results are concerned, the Bentall procedure has also been shown to provide optimal survival with improved functional status. Joo et al. (17), reported survival rates at $1,5,10,20$, and 25 years to be $90.4 \%$, $82.7 \%, 77.6 \%, 65.3 \%$ respectively while freedom from reoperation rates at $1,5,10,20$, and 25 years were $99.0 \%$, 98.3\%, 95.5\%, 90.8\%, and 90.8\%, respectively. Zehr et al. (5), and Kim and colleagues (18), report comparable survival rates and freedom of reoperation.

Gott and colleagues (19), in a milestone paper, evaluated 675 Marfan syndrome (MFS) patients of which 604 had a composite valve graft replacement (CVGR) with excellent outcomes. The reported 5 -year cumulative survival after aortic root replacement was $85 \%$, while the operative mortality was $1.5 \%, 2.5 \%$, and $11.7 \%$ for elective, urgent and emergent repair respectively (19). Our reported results especially in terms of overall survival rates [93.0\% ( $\mathrm{SE}=3.0 \%)$ at 6 months, $93.0 \%(\mathrm{SE}=3.0 \%)$ at 1 year, $89 \%(\mathrm{SE}=5.0 \%)$ at 5 years and $73.0 \%(\mathrm{SE}=5.0 \%)$ at 10,15 and 18 years] confirm the endurance and effectiveness of this procedure in the treatment of aortic root pathology.

Bentall procedure however, has also some well recognized caveats. It is an operation involving the aortic root and as such, the surgeon must be aware of its many pitfalls. Therefore, it should be carried out with great care and in the hands of experienced surgeons. Increased anastomotic tension and large size of coronary buttons have been incriminated for false or true coronary button aneurysms, button kinking and periaortic fistulas $(20,21)$. In this respect, our method of performing the RCA button to valved-graft anastomosis in the end carries significant benefits, as it allows the surgeon to measure the exact site of the RCA button and thereby produce a tension free anastomosis. All the right coronary button anastomoses were constructed with specific care to avoid any kinking. Furthermore, no revision of the right button or a bypass graft to the RCA was required. In this respect, we did not observe any right ventricular (RV) dysfunction coming off bypass except the usual transient RV dysfunction which is occasionally observed and is mainly attributed to air. 
Moreover, no RV dysfunction was observed in the postbypass transesophageal echocardiogram (TOE). The importance of the proper construction of the RCA button anastomosis has been stressed by other authors. Sultan et al. (22), in their paper on how to teach an AVS procedure, emphasize that implantation of the RCA button should be done as high as possible to avoid any potential kinking. It should be noted that the concept of our modification (distal first-RCA last) can be applied in AVS operations as well, however, it would be more technically demanding as the surgeon has to fashion the anastomosis in much less space in the neo-Valsalva sinuses.

Cabrol and colleagues (23), devised a widely known procedure which was advertised to accommodate all the problems involving the tension of buttons. In cases which involve extreme aortic dilatation or calcification or in redo procedures that may hinder tension-free button anastomosis the Cabrol procedure represents a valid choice. However, this procedure has been associated with more problems than the arterial button technique and has led most surgeons to abandon it (24).

Some authors still acknowledge though, that in cases of aortic root re-replacement it is likely that one or both coronary arteries may not reach the new aortic root without tension (25). According to Raanani et al. (25), it is advised that a short segment of saphenous vein or Dacron graft may be used to increase length. In fact, 16 out of the 34 described patients of their study, required extension of one or both coronary arteries (25). In our series we describe ten patients with redo root replacement for a variety of previous procedures (Table 1). We have utilized this graft elongation technique in only one patient who had CABG in the past. We believe that our low reported rate of utilization of this technique was augmented from the use of Valsalva graft. Furthermore, we recognize that use of the Valsalva conduit confers significant benefits in terms of reduced tension during button suturing and incidence of pseudoaneurysms. From 2009 onwards, we have switched our practice to exclusive use of the Valsalva graft. The comparison between the straight and the Valsalva did not yield any statistically significant differences (log-rank test, $\mathrm{P}=0.407)$ Nevertheless, we believe that the absence of reported pseudoaneurysms on long-term follow-up was fostered by (I) implementing the small button technique ( $<5 \mathrm{~mm}$ ), (II) distal first-RCA last configuration and (III) use of Valsalva graft.

Other considerable shortcomings deriving from the use of the mechanical valved conduit are those associated with life-long anticoagulation, new bleeding events, risk of endocarditis and pannus formation. Complications related to thromboembolism and anticoagulation deriving from mechanical composite graft surgery are well documented in literature. Mookhoek and colleagues in a comprehensive systematic review and meta-analysis comprised 46 studies with 7,629 patients who had aortic root surgery (26). In total, $93.2 \%$ of these patients underwent the Bentall procedure with a mechanical valved conduit. The authors report outcomes events as linearized occurrence rates (percentage per patient year). They report $0.64 \%$ rate for hemorrhage and $0.77 \%$ for thromboemboli. During our follow-up the occurrence of new bleeding events was $3.3 \%$ while none of our patients experienced a thromboembolic episode. The majority of our patients received a mechanical conduit, mainly due to the relatively low mean age [3,57]. It should be noted that, in the following years, due to the transcatheter aortic valve implantation (TAVI), we might witness an increase in the number of bioprosthetic conduits (bio-Bentall). The rationale is obvious. In these patients however, coronary height should be thoroughly checked as coronary obstruction carries a high risk of fatality (27).

During the last 10 to 15 years, the Bentall's major "adversary" has been the AVS procedure (either the David reimplantation or the Yacoub remodeling). Bentall is more popular than the AVS because its learning curve is less steep rendering it more reproducible. The use of AVS, however, has expanded in the last years due to encouraging reported results $(28,29)$ and has been embraced with enthusiasm. Specialized centers report reduced cardiac mortality and valve-related morbid event rates for AVS when compared with composite valve graft surgery (30).

Nonetheless, AVS has some inherent limitations. Sparing the aortic valve during root replacement is not feasible in some instances. Morphology of the cusps, i.e., calcific degeneration, thin aortic cusps, leaflet redundancy or fenestrations which are most prominent in the context of Marfan's fibrillin deficiency and infective endocarditis may limit the choice for opting the AVS. Moreover, surgeon inexperience and concomitant procedures may prolong cross-clamp time thus, narrowing the use of AVS (31). Additionally, AVS carries the potential need for reoperation on the aortic valve mainly due to recurrent AI (32). Benedetto and colleagues (33), in a systematic review and meta-analysis reported a nearly 4-time higher probability of reoperation after AVS compared to composite graft in Marfan patients (1.3\%/year vs. $0.3 \% /$ year). Coselli et al., in a recent multicenter registry reported a concerning $7 \%$ of 
failure rate (grade $\geq 2+\mathrm{AI}$ ) at 1-year after AVS in patients with MFS (34). The authors underline the importance of 5- and 10-year follow-up to evaluate the long-term durability of AVS in this group of patients.

Finally, another potential weakness in AVS operations, especially in the "reimplantation" technique (David procedure), is that in order to perform the root part of the procedure, the graft has to be divided. This necessitates an additional graft to graft anastomosis to complete the replacement of ascending aorta and potentially increases operation times and risk for bleeding. On the other hand, the Bentall procedure offers a more complete repair of the ascending aorta using a single graft. Similarly, the "remodeling" operation (Yacoub procedure) fails to stabilize the aortic annulus while the Bentall procedure effectively addresses annular dilatation which represents one of the major issues of annuloaortic ectasia (35).

\section{Limitations}

This is a small retrospective series from a single center with mid- to long-term clinical follow-up. The main limitations of this study stem from its retrospective nature as well as from the incomplete data collection which made us omit some variables from the statistical analysis. Followup computed tomography imaging was not routinely performed. Follow-up is still ongoing.

\section{Conclusions}

Bentall button technique is considered one of the most curative procedures in surgery and remains the best option for the average cardiac surgeon who deals with aortic root pathology. This is a small series from a single center for the Bentall procedure. The overall good short and long-term results of this study have shown that in specialized centers, Bentall procedure even when combined with other cardiac procedures, is associated with low mortality and reduced complication rates while it promotes LV remodeling. Bentall can still be regarded as a very efficient and durable procedure and remains the gold standard operation for patients who need aortic root replacement.

\section{Acknowledgements}

None.

\section{Footnote}

Conflicts of Interest: The authors have no conflicts of interest to declare.

Ethical Statement: This study was approved by Athens Medical Center Institutional Review Board (protocol number 3345, 6th March 2018).

\section{References}

1. Cooley DA, De Bakey ME. Resection of entire ascending aorta in fusiform aneurysm using cardiac bypass. J Am Med Assoc 1956;162:1158-9.

2. Bentall $\mathrm{H}, \mathrm{De}$ Bono A. A technique for complete replacement of the ascending aorta. Thorax 1968;23:338-9.

3. David TE. Remodeling the aortic root and preservation of the native aortic valve. Oper Tech Card Thorac Surg 1996;1:44-56.

4. Yacoub M. Valve-conserving operation for aortic root aneurysm or dissection. Oper Tech Card Thorac Surg 1996;1:57-67.

5. Zehr KJ, Orszulak TA, Mullany CJ, et al. Surgery for aneurysms of the aortic root: a 30-year experience. Circulation 2004;110:1364-71.

6. Celiento M, Ravenni G, Margaryan R, et al The Modified Bentall Procedure: A Single-Institution Experience in 249 Patients with a Maximum Follow Up of 21.5 Years. J Heart Valve Dis 2016;25:448-55.

7. O'Brien MF, Harrocks S, Stafford G, et al. Allograft aortic root replacement in 418 patients over a span of 15 years: 1985 to 2000. Semin Thorac Cardiovasc Surg 2001;13:180-5.

8. Kon ND, Riley RD, Adair SM, et al. Eight-year results of aortic root replacement with the Freestyle stentless porcine aortic root bioprosthesis. Ann Thorac Surg 2002;73:1817-21.

9. Cox DR. Regression models and life tables. J R Stat Soc (B) 1972;34:187-202

10. Cabrol C, Pavie A, Mesnildrey P, et al. Long-term results with total replacement of the ascending aorta and reimplantation of the coronary arteries. J Thorac Cardiovasc Surg 1986;91:17-25.

11. Kouchoukos NT, Marshall WG, Wedige-Stecker TA. Eleven-year experience with composite graft replacement of the ascending aorta and aortic valve. J Thorac Cardiovasc Surg 1986;92:691-705.

12. Westaby S, Katsumata T, Vaccari G. Aortic root 
replacement with coronary button re-implantation: low risk and predictable outcome. Eur J Cardiothorac Surg 2000;17:259-65.

13. Verbakel KM, van Straten AH, Hamad MA, et al. Results of one hundred and seventy patients after elective Bentall operation. Asian Cardiovasc Thorac Ann 2012;20:418-25.

14. Schachner T, Vertacnik K, Nagiller J, et al. Factors associated with mortality and long-time survival in patients undergoing modified Bentall operations. J Cardiovasc Surg (Torino) 2005;46:449-55

15. Hagl C, Strauch J, Spielvogel D, et al. Is the Bentall procedure for ascending aorta or aortic valve replacement the best approach for long term event-free survival? Ann Thorac Surg 2003;76:698-703.

16. Benke K, Agg B, Szabó L, et al. Bentall procedure: quarter century of clinical experiences of a single surgeon. J Cardiothorac Surg 2016;11:19.

17. Joo HC, Chang BC, Youn YN, et al. Clinical experience with the Bentall procedure: 28 years. Yonsei Med J 2012;53:915-23.

18. Kim TS, Na CY, Oh SS, et al. Long-term mortality and morbidity after button Bentall operation. J Card Surg 2013;28:280-4.

19. Gott VL, Greene PS, Alejo DE, et al. Replacement of the aortic root in patients with Marfan's syndrome. N Engl J Med 1999;340:1307-13.

20. Meijboom LJ, Nollen GJ, Merchant N, et al. Frequency of coronary ostial aneurysms after aortic root surgery in patients with the Marfan syndrome. Am J Cardiol 2002;89:1135-8.

21. Ueno M, Imada T, Nonaka K, et al. Aortopulmonary fistula after aortic root replacement. Ann Thorac Surg 2002;74:590-1.

22. Sultan I, Komlo CM, Bavaria JE. How I Teach a Valve-Sparing Root Replacement. Ann Thorac Surg 2016;101:422-5

23. Cabrol C, Pavie A, Gandjbkhch I, et al. Complete replacement of the ascending aorta with reimplantation of the coronary arteries: new surgical approach. J Thorac Cardiovasc Surg 1981;81:309-15.

Cite this article as: Karangelis D, Tzertzemelis D, Demis AA, Economidou S, Panagiotou M. Eighteen years of clinical experience with a modification of the Bentall button technique for total root replacement. J Thorac Dis 2018;10(12):67336741. doi: $10.21037 /$ jtd.2018.11.61
24. Gelsomino S, Frassani R, Da Col P, et al. A long-term experience with the Cabrol root replacement technique for the management of ascend- ing aortic aneurysms and dissections. Ann Thorac Surg 2003;75:126-31.

25. Raanani E, David TE, Dellgren G, et al. Redo aortic root replacement: experience with 31 patients. Ann Thorac Surg 2001;71:1460-3.

26. Mookhoek A, Korteland NM, Arabkhani B, et al. Bentall Procedure: A Systematic Review and Meta-Analysis. Ann Thorac Surg 2016;101:1684-9.

27. Sultan I, Siki M, Wallen T, et al. Management of coronary obstruction following transcatheter aortic valve replacement. J Card Surg 2017;32:777-81.

28. Kallenbach K, Pethig K, Schwarz M, et al. Valve sparing aortic root reconstruction versus composite replacementperioperative course and early complications. Eur J Cardiothorac Surg 2001;20:77-81.

29. Álvarez-Cabo R. Sparing aortic valve techniques J Thorac Dis 2017;9:S526-32.

30. Ouzounian M, Rao V, Manlhiot C, et al. Valve Sparing Root Replacement Compared With Composite Valve Graft Procedures in Patients With Aortic Root Dilation J Am Coll Cardiol 2016;68:1838-47.

31. Van Nooten GJ, Caes F, Francois K, et al. Twenty years' single-center experience with mechanical heart valves: a critical review of anti- coagulation policy. J Heart Valve Dis 2012;21:88-98.

32. Badiu CC, Voss B, Dorfmeister M, et al. Valve sparing root replacement: where are the limits? Tex Heart Inst J 2011;38:661-2.

33. Benedetto U, Melina G, Takkenberg JJ, et al. Surgical management of aortic root disease in Marfan syndrome: a systematic review and meta-analysis. Heart 2011;97:955-8.

34. Coselli JS, Volguina IV, LeMaire SA, et al. Early and 1-year outcomes of aortic root surgery in patients with Marfan syndrome: a prospective, multicenter, comparative study. J Thorac Cardiovasc Surg 2014;147:1758-66, 1767.e1-4.

35. Liu L, Wang W, Wang X, et al. Reimplantation versus remodeling: a meta-analysis. J Card Surg 2011;26:82-7. 